\title{
Authorial Stance in Thai Students' Doctoral Dissertation
}

\author{
Kunyarut Getkham ${ }^{1}$ \\ ${ }^{1}$ Graduate School of Language and Communication, National Institute of Development Administration (NIDA), \\ Bangkok, Thailand \\ Correspondence: Kunyarut Getkham, Graduate School of Language and Communication, National Institute of \\ Development Administration (NIDA), Bangkok, Thailand. Tel: 662-727-3156. E-mail: kgetkham@yahoo.com
}

\author{
Received: January 10, 2015 Accepted: February 11, 2016 Online Published: February 13, 2016 \\ doi: 10.5539/elt.v9n3p80 URL: http://dx.doi.org/10.5539/elt.v9n3p80
}

\begin{abstract}
This study investigates how linguistic devices are used to convey authorial stance in 36 Introduction sections and 36 Discussion sections of doctoral dissertations written in English by Thai students graduated in language education from different universities in the United States during the period 2008 to 2013. It also compares the use of authorial stance in the two sections. A concordance program called 'AntConc' was used to detect authorial stance based on Hyland (2005)'s framework. The results of an independent sample t-test revealed that there were some sectional differences in the amounts, types, and functions of authorial stance. Pedagogical implications for EAP/ESP instruction and recommendations for further research are provided in light of empirical data.
\end{abstract}

Keywords: authorial stance, academic writing, corpus-based study, English for academic/specific purposes, Thai students

\section{Introduction}

To effectively write Introduction and Discussion sections of dissertations, writers need to position themselves and persuade readers to accept their claims. In so doing, they have to be able to produce appropriate critical comments, judge or make comments concerning empirical evidence and present their own findings. In contrast with the traditional view that academic discourse should be constrained within the borders of objectivity, the manifestation of stance and projection of authorial identity in academic writing has recently been accepted in different academic discourse communities. As a matter of fact, most studies in this field of knowledge in the past decade have come into a common contention that the extent by which writers appropriately and effectively utilize linguistic items - thereby making the text more interactional and engaging with the readers - has been considered as a significant indication of their competence in writing. Within the realm of academic writing there are several types of stance devices and each type performs different functions such as hedging, boosters, attitudinal markers and self-mentions. Several studies were conducted to explore various types of stance using a corpus-based approach (Reilly et al., 2005; Biber, 2006; Hyland, 2008c; McGrath \& Kuteeva, 2012), while some examined a particular type and function of stance. The results reveal that not only have stance devices been used to reach the requirements of the academic community but have also been used for other purposes. For example, hedging and boosters were used to protect authors from any criticism and to indicate a degree of confidence (Hu \& Cao, 2011; Serholt, 2012; Vázquez \& Giner, 2009), attitudinal markers were used to express authors' viewpoints and evaluations (Ahmad \& Mehrjooseresht, 2012), and self-mentions were used to explicitly promote authors as reliable members of the field or to establish a relationship with readers (Dueñas, 2007; Hyland, 2003, 2008; Silver, 2003; Zareva, 2013). Moreover, some studies demonstrated that establishing the author's credibility is a noticeable function of all stance types (Ahmad \& Mehrjooseresht, 2012; Dueñas, 2007; Hu \& Cao, 2011; Hyland, 2003; McGrath \& Kuteeva, 2012; Serholt, 2012).

Several studies have addressed how writers present and evaluate findings (Bamford, 2005; Hunston, 2005; Hyland, 2004, 2005; Hyland \& Tse, 2004). The writer's stance has been addressed from different viewpoints. For example, Biber defines this stance as "the ways in which an author or speaker overtly expresses attitudes, feelings, judgments, or commitment concerning the message" (1988, p. 204). Evidence of stance can be found in several linguistic devices such as lexical items (e.g. adjectives expressing evaluation, or choice of reporting verb). Concern about the concept of evaluation and how it is realized in academic texts has increased (Conrad \& Biber, 2000; Halliday, 1994; Hunston, 2000; Hyland, 2005; Hyland \& Tse, 2004; Silver, 2003; Thompson \& Hunston, 2000). However, among the studies mentioned above, little is known about how researchers who are EFL 
students, especially Thais, utilize stance devices in their research. To be more specific, there are few studies investigating stance employed in dissertations written by EFL students, especially, Thai doctoral students. To the best of my knowledge, only five studies (Ahmad \& Mehrjooseresht, 2012; Gil-Salom \& Soler-Monreal's, 2014; Hyland, 2005; Ozdemir \& Longo, 2014; Rahimivand \& Kuhi, 2014) were conducted to investigate authorial stance of EFL graduate dissertations. To this end, I intend to conduct a corpus-based study to explore the use of authorial stance in the Introduction and Discussion sections of the dissertations since the $\mathrm{PhD}$ dissertations are important pieces of papers-gateway to academic achievement, the researchers must not only process evaluative thinking but creditably express their own evaluations to show their standpoint. This study can shed light on how Thai doctoral students convey their authorial stance in the two sections and it will help EFL/ESL researchers efficiently express their claims and increase their expertise, because the use of authorial stance is itself a valuable tool to foster research writing that makes for better researchers, and publication in respected journals and strengthens the scientific process while playing a crucial role in career advancement. The following research questions are, thus, proposed.

\section{Research Questions}

1) Is there a variety of linguistic devices conveying authorial stance in the Introduction and Discussion sections of the dissertations? If so, which type is most commonly used? What are the functions of stance devices?

2) Do differences exist in the use of authorial stance in the Introduction and Discussion sections of the dissertations?

\section{Corpus and Method}

The corpus consisted of 36 Introduction sections and 36 Discussion sections of doctoral dissertations written in English by Thai students graduated in language education from different universities in the United States during the period 2008 to 2013. Dissertations included were randomly selected. Introduction sections were selected as these are a potentially fruitful place to look for evidence of authorial stance. It is in this section that writers typically show that they have understood the existing research and are able to situate their own research in this context (Henderson \& Barr, 2010, p. 248). In addition, Hyland $(2005,2008)$ stated that in the Discussion sections writers have to be able to produce appropriate critical comments, judge or make comments concerning empirical evidence and their own findings. Thus, it is interesting to compare the use of authorial stance employed in these two sections and see how stances are employed by these researchers.

\subsection{Selection of Dissertations}

A random selection of 36 dissertations written in English by Thai students mentioned above was made. Six dissertations were drawn from a pool of each year. These 36 dissertations were from the ProQuest dissertation database available at the NIDA E-library. The two sections of each dissertation were then downloaded and transformed into .txt format using Microsoft Notepad. All footnotes, quotations, bibliographies, linguistic examples, tables and figures which appeared in the dissertations were excluded from the data because, according to Dahl (2004, p. 1817),"... they may easily skew the results for this category, as one or a few articles may yield a very high total number of such items." Thus, the total corpus contains approximately 291,904 words of running text. This includes the Introduction sections (67,818 words or $23 \%$ of the corpus), and the Discussion sections ( 224,806 words or $77 \%$ of the corpus). It is obvious that the Discussion section is the larger section (See Figure $1)$.

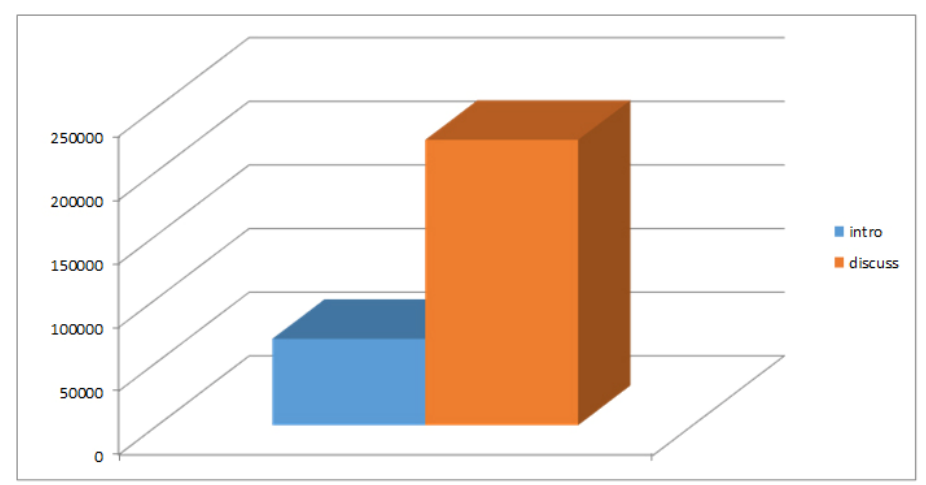

Figure 1. Numbers of words in introduction and discussion sections of the whole corpus 
The details of words in each text are presented in Table 1.

Table 1. Summary of 36 introductions and 36 discussions included in the corpus

\begin{tabular}{|c|c|c|}
\hline Dissertation & Introduction & Discussion \\
\hline $\mathrm{T} 1$ & 1886 & 8,916 \\
\hline $\mathrm{T} 2$ & 2577 & 3,378 \\
\hline $\mathrm{T} 3$ & 543 & 2,530 \\
\hline $\mathrm{T} 4$ & 6114 & 11,638 \\
\hline T5 & 2442 & 1,597 \\
\hline T6 & 1662 & 5,377 \\
\hline $\mathrm{T} 7$ & 996 & 5,662 \\
\hline $\mathrm{T} 8$ & 1315 & 5,190 \\
\hline T9 & 2000 & 5,396 \\
\hline $\mathrm{T} 10$ & 1606 & 5,336 \\
\hline $\mathrm{T} 11$ & 845 & 5,089 \\
\hline $\mathrm{T} 12$ & 2000 & 7,064 \\
\hline $\mathrm{T} 13$ & 2603 & 3,567 \\
\hline $\mathrm{T} 14$ & 1398 & 1,841 \\
\hline $\mathrm{T} 15$ & 2115 & 13,604 \\
\hline T16 & 1749 & 4,087 \\
\hline $\mathrm{T} 17$ & 2200 & 12,503 \\
\hline $\mathrm{T} 18$ & 1434 & 1,775 \\
\hline T19 & 3190 & 6,490 \\
\hline $\mathrm{T} 20$ & 872 & 5,503 \\
\hline $\mathrm{T} 21$ & 1373 & 8,717 \\
\hline $\mathrm{T} 22$ & 743 & 872 \\
\hline $\mathrm{T} 23$ & 885 & 20,546 \\
\hline $\mathrm{T} 24$ & 1732 & 10,503 \\
\hline $\mathrm{T} 25$ & 1689 & 2,452 \\
\hline $\mathrm{T} 26$ & 1939 & 5,146 \\
\hline $\mathrm{T} 27$ & 1041 & 6,345 \\
\hline $\mathrm{T} 28$ & 876 & 5,864 \\
\hline $\mathrm{T} 29$ & 4811 & 2,918 \\
\hline $\mathrm{T} 30$ & 1283 & 3,127 \\
\hline $\mathrm{T} 31$ & 1417 & 1,908 \\
\hline T32 & 1886 & 3,770 \\
\hline $\mathrm{T} 33$ & 2158 & 4,724 \\
\hline $\mathrm{T} 34$ & 3595 & 4,875 \\
\hline T35 & 1026 & 2,096 \\
\hline $\mathrm{T} 36$ & 1817 & 23,680 \\
\hline Total & 67,818 & 224,086 \\
\hline
\end{tabular}




\subsection{Lexical Devices under Study}

Criteria for the identification of authorial stance (See Appendix for the source of lexical devices under investigation.) are based on Hyland's model (2005) since this model was utilized in several studies (e.g. Mur Dueñas,2010; Lee, 2011; Marković, 2013) However, due to the time constraint, I did not include engagement markers.

\subsection{Data Analysis}

In an effort to answer the first and second research questions - the most frequently used stance type and the most frequently used device in each type of stance - I used a concordance, program called 'Antconc' (Anthony, 2013) to detect and attitudinal markers, hedges, boosters, and self-mentions, found in the corpus.

AntConc is a freeware concordancing program which works best with texts in .txt or .xml format, to find the frequency of each device in each stance type. Then these frequencies were recorded in a spreadsheet. When text length is varied, as in this study, Biber (1995) suggests that the frequencies should be normalized. Therefore, the raw frequencies were normalized following Biber's (1995) method by having the raw frequency count divided by the number of words in the text and multiplied by 1000. After that the normalized frequency of each device was recorded. Then the normalized frequencies of all devices in each stance type were added to produce the total number of each stance type. These normalized data were then analyzed.

Descriptive statistics were used to find the frequencies and averages of authorial stance employed throughout in Introduction and Discussion sections. The independent sample t-test was used to determine the differences between the two sections in the use of authorial stance.

\section{Results, Discussions, Limitations, and Implications}

\subsection{Most Commonly Used Authorial Stance}

The results of the analysis are shown in the following table.

Table 2. Averages of authorial stance types in each section

\begin{tabular}{lll}
\hline Stance Type & Mean & SD \\
\hline Attitudinal markers & 13.99 & 6.74 \\
Introduction & 14.34 & 6.68 \\
Discussions & & \\
Boosters & 9.32 & 4.60 \\
Introduction & 11.63 & 4.49 \\
Discussions & & \\
Hedges & 23.42 & 15.73 \\
Introduction & 110.81 & 99.35 \\
Discussions & & \\
Self-mention & 3.83 & 7.78 \\
Introduction & 6.64 & 19.24 \\
Discussions &
\end{tabular}

Table 2 shows that the average of each authorial stance type in the Discussion section is greater than that in the Introduction section. In the both sections, hedges are most frequently employed. This is followed by attitudinal markers, boosters, and self-mentions. The following figure illustrates the averages of authorial stance types in each section. 


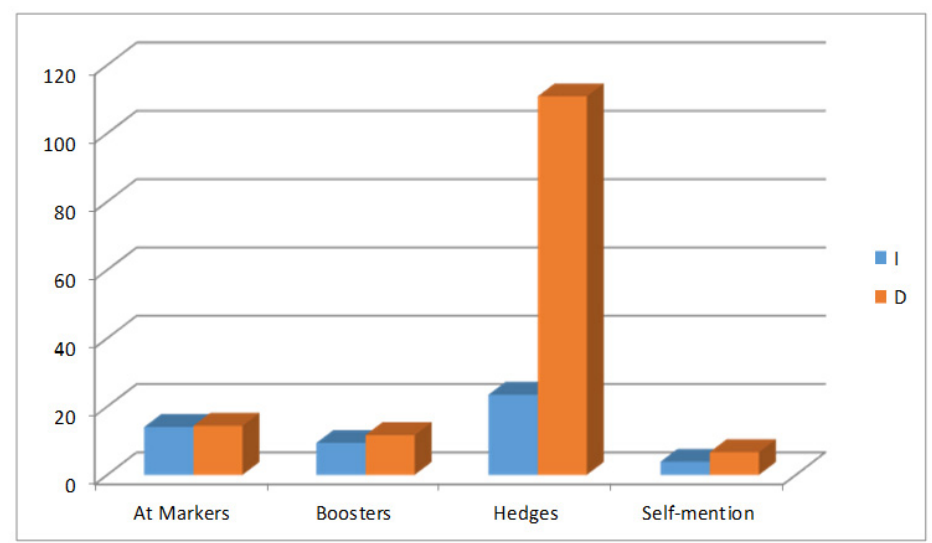

Figure 2. Averages of authorial stance types in each section

In the next parts, each stance type is presented and discussed.

\subsubsection{Attitudinal Markers}

The results of the analysis are shown in the following table.

Table 3. Averages of attitudinal devices in each section

\begin{tabular}{llll}
\hline & Dissertation section & Mean & SD \\
\hline Adjectives & Introduction & 9.77 & 6.13 \\
Adverbs & Discussion & 9.94 & 4.54 \\
& Introduction & 1.57 & 1.10 \\
Nouns & Discussion & 1.99 & 1.97 \\
& Introduction & 1.00 & 1.15 \\
Verbs & Discussion & 1.10 & 1.32 \\
& Introduction & 1.67 & 1.63 \\
all attitudinal markers & Discussion & 1.31 & 1.44 \\
& Introduction & 13.99 & 6.74 \\
& Discussion & 14.34 & 6.68 \\
\hline
\end{tabular}

Table 3 shows that in the two corpora, though there are different lexical categories that manifest attitudinal appraisal, the manifestations of this type of authorial stance in the Introduction and Discussion sections are quite equal with the averages of 13.99 and 14.34, respectively. In both corpora, evaluative adjectives are the most common manifestations of attitude markers and the average of use of this device is nearly equal (9.77 and 9.94 respectively). This finding is consistent with that of Gil-Salom and Soler-Monreal's (2014) in that both English and Spanish PhD writers mostly employed attitudinal adjectives. However, the second most in each section is not the same. In the Introduction, the second most frequent is verbs (1.67) whereas in the Discussions, the second most frequent is adverbs (1.99). The least frequently used device in each section is nouns (1.00 and 1.10 respectively). This is illustrated in the following figure. 


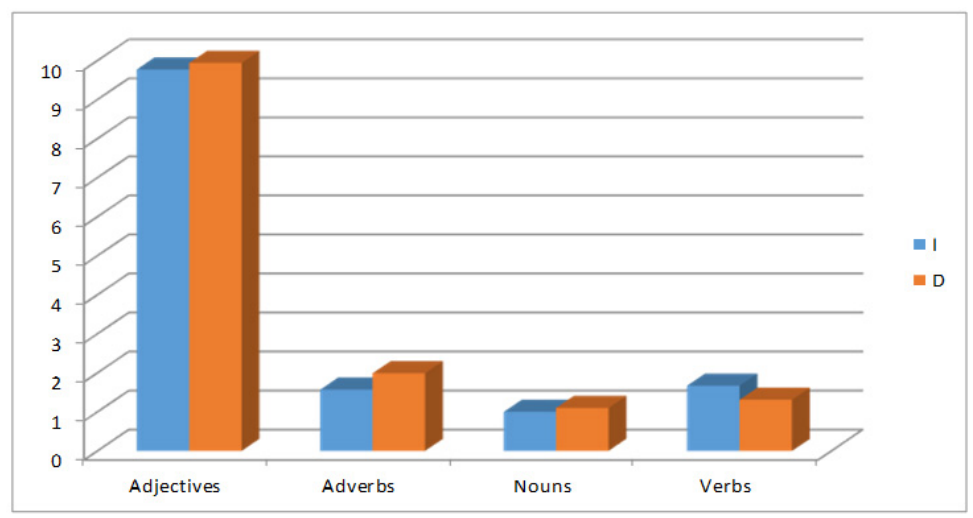

Figure 3. Averages of attitudinal devices in each section

Regarding the Introduction sections, the high use of attitudinal markers reflected authors' subjective attitudes in relation to the content rather than commitment to the truth (Aksu-Koç, 1988, as cited in Reilly et al., 2005). Among these four domains, adjectives (e.g. significant, interesting, and important) seemed to enjoy the highest frequency of use. These writers were less likely to use verbs, adverbs, and nouns. This finding is consistent with several studies ((Koutsantoni, 2004; Stotesbury, 2003; Swales \& Burke, 2003). Such attitudinal adjectives make a particular text more subjective as they add either a positive or negative judgment to the modified noun, and reflect the writers' favorable position towards the modified noun. Writers also capitalize on positive evaluative adjectives to accentuate the significance of the research area and function. In this study, Thai doctoral students utilized evaluative adjectives to show a positive or negative evaluation of previous research, methods, models etc. The fact that adjectives were most frequently employed suggests that these student writers may assume that QUALITY, designated by an adjective, is stable enough to build up associations of approval or disapproval (Bolinger, 1980).

Although adjectives are the most frequently used attitudinal markers in the Introduction, which also agrees with previous research, adjectives are not the only present attitudinal markers because adverbs, nouns and verbs were also found to reflect attitudes of the writers. Results revealed that attitudinal adverbs are next to attitudinal adjectives in terms of averages of use in the corpus. A number of lexical items included in this category are what Conrad and Biber (2000) consider as attitudinal stance adverbs that express feelings or anticipations (e.g. unfortunately, fortunately, surprisingly, amazingly). Intensifying adverbs like truly were also used to highlight an appreciation towards presented information. The finding that attitudinal marker nouns were rarely employed is consistent with that of Charles (2003). The following sentences illustrate the above usages.

1) Nonetheless, the question of how Ixland IV is distributed syllable-finally and what factors underlie their L2 production is an interesting one. (Introduction 10). In this scenario, the writer opted to use an attitude marker to convey importance and applies its relevance to the research study. Also the decision to use interesting implies that the information could be unusual or unorthodox.

2) One problem I have observed during my eight years of teaching experience is that many Thai students lack knowledge of common English expressions. (Introduction 6) In this sentence, a noun "problem" and a verb "lack" were used to mark a negative stance towards Thai students' knowledge of common English expressions.

3) This will in turn contribute to constructing theories defining L2 communicative competence (Introduction 1) In this sentence, a verb "contribute" was used to convey the author's judgment.

4) Surprisingly, the results of the current study contrast with those of previous research that reported a positive impact of planning on the amount of participants' language production. (Discussion 9) In this example, the writer states that he was surprised in the findings. The writer is, therefore, stressing the importance of their statement by supporting it with their own personal judgment.

5) These various language limitations, therefore, made cross-cultural teaching a daunting and frustrating task. (Discussion 15). In this scenario, a noun "limitations" was employed to express the author's view towards cross-cultural teaching.

\subsubsection{Boosters}

The results of the analysis are shown in the following table. 
Table 4. Averages of boosting devices in each section

\begin{tabular}{llll}
\hline Booster devices & Dissertation section & Mean & SD \\
\hline Verb & Introduction & 1.53 & 1.49 \\
Adverb & Discussion & 1.56 & 0.99 \\
& Introduction & 3.29 & 2.11 \\
Adjective & Discussion & 4.51 & 2.47 \\
& Introduction & .94 & 0.92 \\
Modal & Discussion & 1.56 & 0.99 \\
& Introduction & 3.12 & 1.89 \\
Noun & Discussion & 3.26 & 2.96 \\
& Introduction & .44 & 0.64 \\
All devices & Discussion & .74 & 0.79 \\
& Introduction & 9.32 & 4.60 \\
\hline
\end{tabular}

Table 4 shows that in both Introduction and Discussion sections booster adverbs are the most frequently employed device. This finding is consistent with that of Ahmad and Mehrjooseresht (2012) though they analyzed the abstracts of the same discipline. Modal verbs are the second most frequently employed device and nouns are the least frequently employed device. This is illustrated in the following figure.

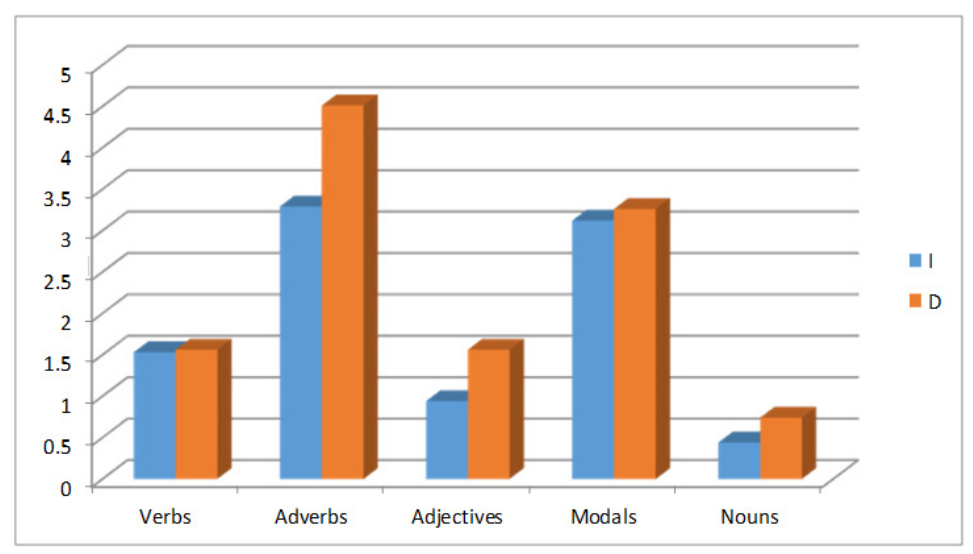

Figure 4. Averages of boosting devices in each section

Findings revealed that the researchers in this study employed boosters to express certainty or to emphasize a point (Dobakhti, 2013; Holmes, 1990; Hyland, 2000; Jalilifar, 2011; Macintyre, 2013). In other words, boosters were used as a certainty marker (Koutsantoni, 2004) or simply as an emphatic (Abdollahzadeh, 2011). They used boosters to put emphasis, add commitment, and express certainty to the claims they made (Holmes, 1990; Hyland, 2000) and to express commitment (Macintyre, 2013). Boosters were tools used to emphasize what writers believed or what they wanted the readers to believe, in other words, increasing force to the propositions (Abdollahzadeh, 2011; Koutsantoni, 2004). Boosters were also used to show a writers' degree of confidence in an assertion (Hyland, 2005, as cited in $\mathrm{Hu} \& \mathrm{Cao}, 2011$ ). The following examples illustrate these usages.

1) There is still a diversity of results in the study of factors that truly affect the EFL students reading strategy use. (Introduction 7) In this sentence, an adverb "truly" was used to express the author's authorial stance towards the factors affecting EFL students reading strategy use.

2) It is evident through the observation that English language learners (ELLs) whose backgrounds are either English as a Second Language or English as a Foreign Language who are international students at colleges and 
universities in the United States are often in that situation. (Introduction 14) In this sentence, a booster adjective "evident" was used to express certainty.

3) This finding seems to be surprising considering the fact that the students were exposed to English medium classes only 15 hours per week for 2 academic years. (Discussion 23). In this sentence, a booster noun "fact" was used to increase the certainty of the claim.

4) While these ideas varied considerably from participant to participant, there was a consensus that listening and speaking skills are of primary importance. (Discussion 20) In this sentence, a booster adverb "considerably" was used to indicate the degree of writer certainty about variation of the ideas.

\subsubsection{Hedges}

The results of the analysis are shown in the following table.

Table 5. Averages of hedging devices in each section

\begin{tabular}{llll}
\hline Hedging Devices & Dissertation Section & Mean & SD \\
\hline Modal & Introduction & 5.68 & 4.22 \\
Lexical verbs & Discussion & 8.80 & 4.44 \\
\multirow{3}{*}{ Adverbs } & Introduction & .79 & 1.06 \\
& Discussion & 1.06 & 1.20 \\
Adjectives & Introduction & 5.19 & 2.53 \\
& Discussion & 6.81 & 3.78 \\
Nouns & Introduction & .60 & 0.73 \\
& Discussion & .95 & 0.62 \\
all hedging devices & Introduction & .28 & 0.78 \\
& Discussion & .69 & 1.06 \\
& Introduction & 23.42 & 15.73 \\
\hline
\end{tabular}

Table 5 shows that there are different lexical categories that manifest hedges. The order of average of use is similar in both the Introduction and Discussion sections. That is, the writers mostly employed modals (5.68 and 8.80) followed by adverbs (5.19and 6.81), lexical verbs (.79 and 1.06), adjectives (.60 and .95), and nouns (.28 and .69)) in the Introduction and the Discussion sections respectively. It is obvious that the manifestation of each hedging device and all hedges in the Discussion section is greater than that in the Introduction section. This is illustrated in the following figure.

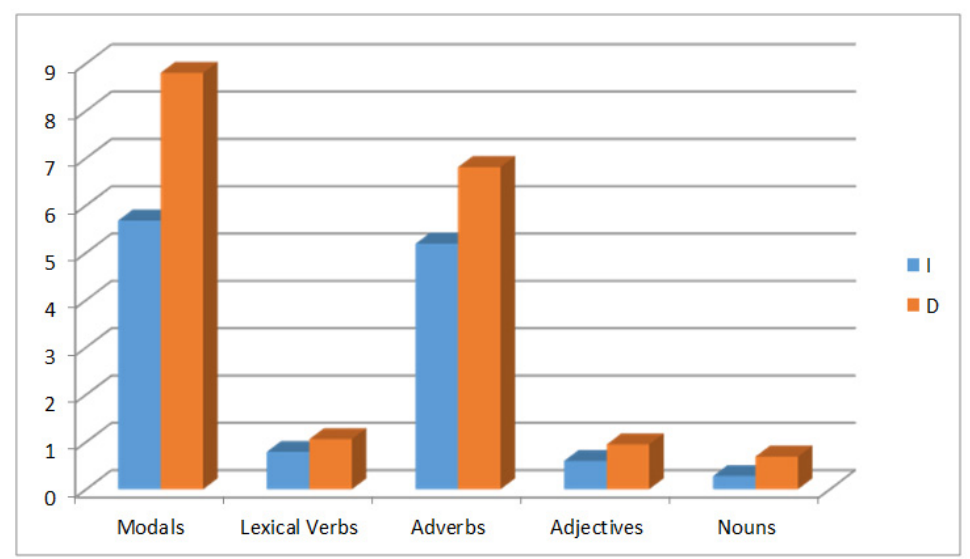

Figure 5. Averages of hedging devices in each section 
Findings that hedges were most commonly used in the Discussion section were consistent with previous works (Burrough-Boenisch, 2005; Falahati, 2009; Lau, 1999; Mirzapour \& Mahand, 2012; Myer, 1989; Salager-Meyer, 1994; Varttala, 1999) but were not consistent with that of Getkham (2012) since she found that the highest incidence of hedges was in the introduction section and the second highest was in the discussion sections of research articles in applied linguistics journals. According to Hyland (1999), the Discussion section contains mainly interpretations or tentative propositions for the research results. Research writers need to gain acceptance for their claims from authorities in their fields and use several strategies aimed at persuading the authority of the truth of their claims. In so doing, hedges are mostly used to mitigate claims or denials of claims (Hyland, 1996).

Hedges can help writers present unproven claims with prudence and mitigate assertions. Hedges can also offer discursive room in which readers are able to contend the writer's arguments and interpretations, thereby enabling writers to take a position or to express their stances with respect to an audience as well as to facts. It is obvious that the writers in this study used hedges to present findings and establish their importance in Discussion sections (Hyland, 1999) as a means of gaining ratification for claims from a powerful peer group (Hyland, 1996), as a means of showing politeness (Getkham, 2013; Myers, 1989; Salager-Meyer, 1994), as a means to express hesitancy that enables the author to open the possibility for alternative views (Martin \&White, 2005; Lee \& Casal, 2014), and as face-saving devices (Halliday, 1994).

Hedging was employed to avoid the commitment of the propositions, to weaken the author's claims, and to display uncertainty about the truth of a statement. These Thai doctoral student writers seem to be careful in terms of expressing the results that they present (Orta, 2010). They, therefore, tend to use more hedges to avoid or minimize face threatening acts when making their claims (Hyland, 2005).

Findings also indicate that modal verb hedges were the most frequently used. This indicates that modal auxiliaries seem to be the most straightforward device to express modality, while lexical verbs serve as a powerful verbal repertoire for RA authors to express epistemic modality via reporting or committing to the propositions of their studies. Moreover, previous research has indicated that textbooks for ESL students seem to emphasize modal verbs as means to convey certainty or probability (Holmes, 1988). Moreover, Hyland (1994) states that ESL teaching materials seemingly neglect to include academic hedging based on an analysis of authentic usage. This may be the reason why the researchers mostly employed modal verbs. The following examples illustrate these usages.

1) Some effective learners might combine certain stages into one. (Discussion, 3) In this sentence, the modal hedge "might" was used to display uncertainty about the truth of a statement.

2) The pre-test and post-test show that approximately $91 \%$ of the students in this study demonstrated an improvement in scores between the pre-test and post-test. (Discussion, 6) In this sentence, adverb hedge "approximately" was used, to avoid commitment of the propositions.

3) Thai people seem to move ahead only, forgetting their past that can teach them where to go wisely. (Introduction 19) In this sentence, lexical verb hedge "seem" was used to mitigate criticism.

Hedges also tend to occur frequently within a negative context as in the following example.

1) This also signals the possibility that teachers, parents, researchers, and maybe even learners do not appreciate many of the out-of-class language activities as language learning sources.(Introduction, 8) In this negative context, a noun hedge "possibility" was employed to weaken the degree of the writer's claim.

2) Because they have difficulty in translating from their native tongue into English, and because of other factors like lack of confidence and misleading teaching methods, expressing the level of critical thinking is probably more difficult. (Discussion 12) In this negative context, an adverb hedge "probably" was employed to weaken the degree of writer's claim.

3) Apart from the aforementioned issues with previous pragmatic studies, the current study is also motivated by the relative scarcity of L2 research on the role of learning settings or environments in L2 performance. (Introduction, 1) In this negative context, an adjective hedge "relative" was used to avoid author's commitment.

\subsubsection{Self-mentions}

The results of the analysis are shown in the following table. 
Table 6. Averages of self-mentions in each section

\begin{tabular}{llll}
\hline & Dissertation Section & Mean & SD \\
\hline Self-mentions & Introduction & 3.83 & 7.78 \\
& Discussion & 6.64 & 12.94 \\
\hline
\end{tabular}

Table 6 shows that the writers utilize self-mentions in the discussions (6.64) much more than in introduction sections (3.83). See the illustrations in the following figure.

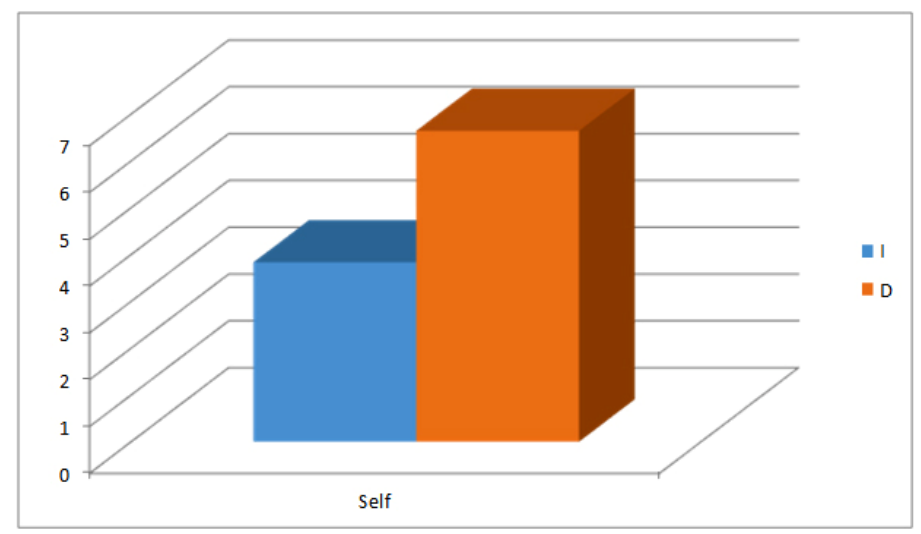

Figure 6. Averages of self-mentions in each section

Finding that the occurrence of self-mention in my study was relatively low when compared with the other three types of stance was consistent with that McGrath and Kuuteva (2012). However, Hyland (2003) stated that with the less clear-cut, precise and measurable nature of soft knowledge, writers tend to employ more self-mentions to present themselves as an informed, reliable colleague and to exhibit their particular views to gain recognition. In addition, Luzon (2009) found that student writers utilized the first person pronoun to express authorial stance more frequently than that of professional writers. My finding indicated the writer's conventional belief that the goal of research is to be impersonal. Nevertheless, the higher frequency of occurrences in the Discussion section than in the Introduction section (6.64 and 3.83 respectively) suggests that when discussing, some writers may accept self-mentions as a tool for a more effective means of engaging the readers. In addition, self-mention may be used to show the level of writers "confidence". In the Introduction, the writers in this study may be reluctant about the value of their research whereas in the Discussion, they may be more confident as they see the valuable findings of their research. The following examples illustrate these usages.

1) For the purpose of this dissertation, $I$ will refer to them as ostensible apologies. (Introduction 1) In this sentence, the first pronoun " $I$ " was used to present the author's identity.

2) I hope that $m y$ study will provide another piece of the puzzle involving the complex reciprocal relationship between reading and writing skills. (Introduction 21) In this sentence, " $I$ " was used to present the author's identity and " $m y$ " was used to emphasize and publicize the author's work and contributions.

3) This combination of dries moves $m e$ forward to address a critical issue in applied linguistics. (Introduction 4) In this sentence, " $m e$ " was used to show the writer's existence in the text.

4) People from various nationalities frequently came up to $m e$ and said they felt that a native Thai speaker like myself speak English with musical tones. (Introduction 11) In this sentence, "me" was used to express the writer's identity and "myself" was used to emphasize her national origin.

5) In the Discussion sections, the use of self-mentions can be seen in the following sentences.

6) I will discuss the results of $m y$ investigation of student reading strategy use as compared with other studies on EFL/ESL reading strategies. (Discussion 7) In this sentence, "I" was used to present the author's identity and " $m y$ " was used to emphasize and publicize the author's work and contributions. 
7) By so doing, in the teaching of writing, it goes back to a claim of mine in Chapter I that writing is growth, that is, spiritual growth. (Discussion 12) In this sentence, "mine" was used to emphasize and publicize the author's work and contributions.

8) The research findings lead $m e$ to believe that out-of-class activities help enhance participants' English learning. (Discussion 8) In this sentence, " $m e$ " was used to show the writer's existence in the text.

9) It is through research that $I$ can extend $m y$ understanding of teaching, and so $I$ would like to commit myself to do research for the rest of $m y$ teaching career. (Discussion 21) In this sentence, " $P$ " was used to express the writer's identity, and "my", "myself" were used to emphasize and publicize the author's work and contributions.

In addition to the aforementioned findings, it should be noted that the manifestation of nouns in each stance type was very rare. In fact, it was least frequently utilized. According to Charles (2003), the use of stance marker nouns was important for thesis writers, as it established a valuable resource for the construction of convincing arguments and the expression of appropriate stance. This point will be put forward in the recommendations.

\subsection{Differences in the Use of Authorial Stance in the Introduction and Discussion Sections}

Results of the independent sample t-test are shown in the following table.

Table 7. Differences in the use of authorial stance between the two sections

\begin{tabular}{|c|c|c|c|}
\hline Stance Type & Mean & $\mathrm{SD}$ & Sig \\
\hline \multirow{2}{*}{$\begin{array}{l}\text { Attitudinal } \\
\text { Introduction }\end{array}$} & markers & & \\
\hline & 13.99 & 6.74 & .826 \\
\hline Discussions & 14.34 & 6.68 & \\
\hline \multicolumn{4}{|l|}{ Boosters } \\
\hline Introduction & 9.32 & 4.60 & $.035 *$ \\
\hline Discussions & 11.63 & 4.49 & \\
\hline \multicolumn{4}{|l|}{ Hedges } \\
\hline Introduction & 23.42 & 15.73 & $.001 * * *$ \\
\hline Discussions & 110.81 & 99.35 & \\
\hline \multicolumn{4}{|l|}{ Self-mention } \\
\hline Introduction & 3.83 & 7.78 & .419 \\
\hline Discussions & 6.64 & 19.24 & \\
\hline
\end{tabular}

Table 7 shows that significant differences between the two sections exist in the use of hedges $(\mathrm{P}<.001)$ and in the use of boosters $(\mathrm{P}<.05)$. Generally, the doctoral students employed fewer hedges and boosters in the Introduction section than in the Discussion section ((boosters 9.32 and 11.63; hedges 23.42 and 110.81 respectively). No significant differences are found in the use of attitudinal markers and self-mentions.

Findings that hedges were more frequently used in the Discussion sections of research articles are in line with the findings of Burrough-Boenisch (2005), Lau (1999) and Mirzapour and Mahand (2012). The very high manifestation of hedges in the Discussion section as compared to that observed in the Introduction was due to the fact that the claim is the important part of the Discussion and it is important for these doctoral student writers to utilize hedges as politeness strategies. These writers used hedges to politely qualify or moderate the claims (Hyland, 1998 as cited in Wishnoff, 2000; Getkham, 2013; Myers, 1989; Salager-Meyer, 1994), and as a means of gaining ratification for claims from a powerful peer group (Hyland, 1996).

In addition, Finding that boosters were more frequently used in the Discussion section is consistent with that of Serholt (2012). In her study, the frequency of occurrences in the Introduction was $20 \%$ while that in the Discussion section was $46 \%$. Higher manifestation of boosters in the Discussion suggests that when discussing, writers interpret their results and argue for these results. This is the reason the percentage of boosters was higher in this section. It is obvious that the writers in my study utilized boosters to signal their assurance of the statement they are claiming and serve as essential argument device that increases certainty of the claim (Dobakhti, 2013; Jalilifar, 2011). 
However, no significant differences were found between the Introduction and Discussion sections in the use of attitudinal markers and self-mentions. This finding is consistent with that of Ahmad and Mehrjooseresht (2012). This indicates that in both sections, writers may assume that it is vital to express their attitudes towards the propositions from either established knowledge or from their own findings. It is also interesting to note that these writers, though rarely employing some linguistic devices such as adverbs and nouns, may realize that they should convey their affective value or attitudes towards the propositional content or situation.

In addition, though no significant difference was found in the use of self-mentions, the average of usage of this device in the Discussion section was much more than in the Introduction section (239.07 and 137.77 respectively). In the Discussion section, the writers in this study strategically utilized self-mention as a tool to emphasize and publicize their work and contributions (Harwood, 2005; Hyland, 2001). In so doing, writers can create a more personal and friendlier atmosphere between writers and readers (Dueñas, 2007; Hyland, 2003; Liu \& Chang, 2011; Zareva, 2013).

\section{Conclusions}

Several conclusions can be drawn from the findings of this study. First, academic/research writing is more than presenting a collection of facts. It also presents writers' views and manners (Hyland, 2005). It should be noted that these doctoral students demonstrated their interpersonal interaction skills The use of authorial stance enables them to highlight the value of the claim presented in their paper and express their attitude towards it. As a result, by employing these stances, they efficiently interact with their readers and are able to present themselves as competent writers. Linguistically, authorial stance is realized through various kinds of formal categories such as attitudinal markers, hedges, boosters, and self-mentions.

Hedges were mostly employed, followed by boosters, in the Discussion section. The doctoral students in this study formulated their claims with different levels of strength, ranging from very weak statements to very assertive ones. Hedging and boosters were the two stance types employed for this purpose. The use of hedging and boosting devices in these Thai student dissertations suggested that hedging (being polite) may be culturally inherent. As for the frequency of the attitude markers used in the analyzed academic texts, we may conclude that attitudinal markers play a vital role in stating that the general research area is important, central, interesting, and problematic. They also play a role in emphasizing the value of previous research.

In addition, the traditional nature of research writing may explain the reasoning behind why self-mentions are rarely used in the Introduction and Discussion sections of the dissertations. The conventional belief that the goal of research is to be objective, impersonal, and unbiased could attribute to why writers prefer not to directly mention themselves in their research. In order to maintain a professional and respectful position, the writer may decide that involving themselves in the propositional statement may be detrimental. It is also important to realize that nouns are rarely employed in all stance types. The results of this study echo those of previous research findings. They not only pave the way for further studies in the use of authorial stance but also offer some constructive implications for teaching EAP/ESP.

\section{Limitations of the Study}

Although this research was carefully prepared, I am still aware of its limitations and shortcomings. First of all, the corpus was selected from Thai doctoral students who studied in the United States. It would be better if the corpus included some dissertations from different countries. Second, the population of this study is small, only 36 students and might not represent the majority of the students of the doctoral level. In addition, since the function of each stance type was interpreted by the author herself, it is unavoidable that in this study, certain degree of subjectivity can be found. In fact, it would have been objective if it had been decided by two or three investigators.

\section{Implications for Instruction}

In contrast with the traditional view that academic discourse should be constrained within the borders of objectivity, the manifestation of stance and projection of authorial identity in academic writing has recently been accepted in different academic discourse communities. As a matter of fact, most studies in this field of knowledge in the past decade have come into a common contention that the extent by which writers appropriately and effectively utilize linguistic items - thereby making the text more interactional and engaging with the readers - has been considered as a significant indication of their competence in writing.

Findings from this study provide some insight into the use of authorial stance by these doctoral students in their attempts to produce completed dissertations. It is clear that they need to be made aware of the use of different stance taking devices. It is, therefore, essential that available devices of authorial stance be included in EAP/ESP, given the findings that the use of nouns was found to be the least employed in this study. According to Charles 
(2003), the use of stance marker nouns was important for thesis writers, as it established a valuable resource for the construction of convincing arguments and the expression of appropriate stance. For non-native English speaking students, training in awareness of different kinds of authorial stance as well as point out the relationships among functions and language would enhance their ability to acquire skills in academic writing.

More importantly, the results found in this study may provide pedagogical insights into EAP/ESP. Empirical evidence such as Duenas (2007) indicates that native English speaker use of self-mentions was more frequent than that of non-native speakers. Hence, students should be introduced to the usage of first person pronouns so that they know how to present themselves in academic texts.

In sum, ESP/EAP instructors may make use of the findings of this study in helping students improve their writing for publication in terms of the expressing their authorial stance in their papers. Raising students' awareness of conveying their authorial stance in various ways is also crucial.

\section{Implications for Future Research}

More studies should be conducted to enhance greater understanding of authorial stance used in academic writing, especially cross-cultural differences in the use of authorial stance. Those studies might compare published articles with this genre. Furthermore, it may also be interesting to conduct a meta-analysis of the evolution of the use of self-mentions (i.e. first person pronouns) in dissertations of Thai students graduated from Thai universities during 2000-2010.

\section{References}

Abdollahzadeh, E. (2011). Poring over the findings: Interpersonal authorial engagement in applied linguistics papers. Journal of Pragmatics, 43(1), 288-297. http://dx.doi.org/10.1016/j.pragma.2010.07.019

Anthony, L. (2013). AntConc (Version 3.2.2) [Computer Software]. Tokyo, Japan: Waseda University. Available from http://www.antlab.sci.waseda.ac.jp/

Ahmad, U., \& Mehrjooseresht, M. (2012). Stance adverbials in engineering theses abstracts. Procedia - Social and Behavioral Sciences, 66, 29-36. http://dx.doi.org/10.1016/j.sbspro.2012.11.244

Bamford, J. (2005). Subjective or objective evaluation? Prediction in academic lectures. In E. T. Bonelli, \&d G. Del Lungo Camiciotti (Eds.), Strataegies in academic discourse (pp. 17-29). Amsterdam: BenJamins.

Biber, D. (1995). Variation across Speech and Writing. Cambridge: Cambridge University Press.

Biber, D. (2006). University Language: A corpus-based study of spoken and written registers. Amsterdam/Philadelphia: John Benjamins. http://dx.doi.org/10.1075/scl.23

Bolinger, D. (1980). Language, the loaded weapon: The use and abuse of language today (2nd ed.), New York: Longman.

Burrough-boenisch, J. (2005). NS and NNS scientists' amendments of Dutch scientific English and their impact of hedging. English for Specific Purposes, 24(1), 25-39. http://dx.doi.org/10.1016/j.esp.2003.09.004

Chang, P., \& Schleppegrell, M. J. (2011). Taking an effective authorial stance in academic writing: Making the linguistic resources explicit for L2 writers in the social sciences. Journal of English for Academic Purposes, 10(3), 140-151. http://dx.doi.org/10.1016/j.jeap.2011.05.005

Charles, M. (2003). "This mystery...: A corpus-based study of the use of nouns to construct stance in theses from two contrasting disciplines. Journal of English for Academic Purposes, 2(4), 313-326. http://dx.doi.org/10.1016/S1475-1585(03)00048-1

Conrad, S., \& Biber, D. (2000). Adverbial marking of stance in speech and writing. In S. Hunston, \& G. Thompson (Eds.), Evaluation in text: Authorial stance and the construction of discourse (pp. 56-73). Oxford: Oxford University Press.

Dobakhti, L. (2013). Expressing certainty in Discussion sections of qualitative and quantitative research articles. Journal of Pan-Pacific Association of Applied Linguistics, 17(1), 57-77.

Dueñas, P. M. (2007). 'I/we focus on...' A cross-cultural analysis of self-mentions in business management research articles. Journal of English for Academic Purposes, 6(2), 143-162. http://dx.doi.org/10.1016/j.jeap.2007.05.002

Falahati, R. (2007). The use of hedging across different disciplines and rhetorical sections of research articles. In N. Carter, L. H. Zabala, A. Rimrott, \& D. Storoshenko (Eds.), Proceedings of the 22nd Northwest Linguistics Conference (NWLC) at Simon Fraser University (pp. 99-112). 
Getkham, K. (2012). Hedging devices in applied linguistics research articles. In Andrew J. Werst, \& J. Singhakowinta (Eds.), Proceedings of the $3^{\text {rd }}$ International Conference on Language and Communication (ICLC) at National Institute of Development Administration, Bangkok, Thailand.

Getkham,K. (2013). Politeness strategies in research articles: A cross-disciplinary study. PASAA, 46, 46-74

Gil-Salom, L., \& Soler-Monreal, C. (2014). Writers' positioning in literature reviews in English and Spanish computing doctoral theses. Journal of English for Academic Purposes, 16, 23-39. http://dx.doi.org/10.1016/j.jeap.2014.08.002

Halliday, M. (1994). Introduction to functional grammar (2nd ed.). London: Arnold.

Harwood, N. (2005). We do not seem to have a theory... The theory I present here attempts to fill this gap': Inclusive and exclusive pronouns in academic writing. Applied Linguistics, 26(3), 343-375. http://dx.doi.org/10.1093/applin/ami012

Holmes, J. (1988). Doubt and certainty in ESL textbooks. Applied Linguistics, 9(1), 21-44. http://dx.doi.org/10.1093/applin/9.1.21

Holmes, J. (1990). Hedges and boosters in women's and men's speech. Language and communication, 10(3), 185-205. http://dx.doi:10.1011/0271-5309(90)90002-S

Hunston, S. (2005). Conflict and consensus: Construing Opposition in applied linguistics. In E. Tognni Bonelli and G. Del Lungo Camiciotti (Eds.). Strataegies in academic discourse (pp. 1-15). Amsterdam: BenJamins. http://dx.doi.org/10.1075/scl.19.02hun

Hu, G., \& Cao, F. (2011). Hedging and boosting in abstracts of applied linguistics articles: A comparative study of English- and Chinese-medium journals. Journal of Pragmatics, 43(11), 2795-2809. http://dx.doi.org/10.1016/j.pragma.2011.04.007

Hyland, K. (1994). Hedging in academic writing and EAP textbooks. English for Specific Purposes, 13(3), 239-256. http://dx.doi.org/10.1016/0889-4906(94)90004-3

Hyland, K. (1996). Writing without conviction: Hedging in science research articles. Applied Linguistics, 17(4), 433-454. http://dx.doi.org/10.1093/applin/17.4.433

Hyland, K. (1999). Disciplinary discourse: Writer stance in research articles. In C. Candlin, \& K. Hyland (Eds.), Writing: Texts, processes and practices (pp. 99-121). Harlow: Addison -Wesley Longman.

Hyland, K. (2000). Disciplinary discourses: Social interactions in academic writing, Harlow: Longman.

Hyland, K. (2001). Humble servants of the discipline? Self-mention in research articles. English for Specific Purposes, 20(3), 207-226. http://dx.doi:10.1016/S0889-4901(00)00012-0

Hyland, K. (2002). Authority and invisibility: Authorial identity in academic writing. Journal of Pragmatics, 34(8), 1091-1112. http://dx.doi.org/10.1016/S0378-2166(02)00035-8

Hyland, K. (2005). Stance and engagement: A model of interaction in academic discourse. Discourse Studies, 7(2), 173-191. http://dx.doi.org/10.1177/0741088309357846

Hyland, K. (2008). Persuasion, interaction and the construction of knowledge: Representing self and others in research writing. International Journal of English Studies, 8(2), 1-23.

Hyland, K. (2010). Community and individuality: Performing identity in applied linguistics. Written Communication, 27(2), 159-188. http://dx.doi:10. 1177/0741088309357846

Hyland, K. \& Tse, P. (2004). Metadiscourse in academic writing: A reappraisal. Applied Linguistics, 25(2), 156-177. http://dx.doi.org/10.1093/applin/25.2.156

Jalilifar, A. R. (2011). World of attitudes in research article discussion parts: A cross-linguistic perspective. Journal of Technology of Education, 5(3), 177-186.

Koutsantoni, D. (2004). Attitude, certainty and allusions to common knowledge in scientific research articles. Journal of English for Academic Purposes, 3(2), 163-182. http://dx.doi.org/10.1016/j.jeap.2003.08.001

Lau, H. H. (1999). Hedges expressions as signals of evidence in academic journal discourse. Selected papers from the 8th Symposium on English Teaching (pp. 431-440). Taipei: Crane.

Lee, J.J. \& Casal J.E. (2014) Metadiscourse in results and discussion chapters: A cross-linguistic analysis of English and Spanish thesis writers in Engineering. System, 46, 39-54. http://dx.doi.org/10.1016/j.system.2014.07.009 
Ozdemir, O. N., \& Longo, B. (2014). Metadiscourse use in thesis abstracts: A cross-cultural study. Procedia-Social and Behavioral Sciences, 141, 59-63. http://dx.doi.org/10.1016/j.sbspro.2014.05.011

Luzón, M. J. (2009). The use of we in a learner corpus of reports written by EFL engineering students. Journal of English for Academic Purposes, 8(3), 192-206. http://dx.doi.org/10.1016/j.jeap.2009.04.001

Macintyre, R. (2013) Lost in a forest all alone: the use of hedges and boosters in the argumentative essays of Japanese university students. Sophia International Review, 1-24.

Martin, J., \& White, P. (2005). The language of evaluation. Basingstoke: Palgrave MacMillan. http://dx.doi.org/10.1177/1356389005059385

McGrath, L., \& Kuteeva, M. (2012). Stance and engagement in pure mathematics research articles: Linking discourse features to disciplinary practices. English for Specific Purposes, 31(3), 161-173. http://dx.doi.org/10.1016/j.esp.2011.11.002

Mirzapour, F. \& Mahand, M. R. (2012). Hedges and boosters in native and non-ntive bibrary and information and computer science research articles, The Southeast Asian Journal of Language Studies, 18 (2), 119-128.

Myers, G. (1989). The pragmatics of politeness in scientific articles. Applied Linguistics, 10(1), 1-35. http://dx.doi.org/10.1093/applin/10.1.1

Orta, I. V. (2010). A contrastive analysis of the use of modal verbs in the expression of epistemic stance in business management research articles in English and Spanish. Iberica, 19, 77-95.

Rahimivand, M., \& Kuhi, D. (2014) An Exploration of discoursal construction of identity in academic Writing. Procedia-Social and Behavioral Sciences, 98, 1492-1501. http://dx.doi.org/10.1016/j.sbspro.2014.03.570

Reilly, J., Zamora, A., \& Mcgivern, R. F. (2005). Acquiring perspectives in English: The development of stance. Journal of Pragmatics, 37, 185-208. http://dx.doi.org/10.1016/j.pragma.2004.08.010

Salager-Meyer, F. (1994). Hedges and textual communicative function in medical English written discourse. English for Specific Purposes, 13(2), 149-170. http://dx.doi:10.1016/0889-4906(94)900013-2

Serholt, S. (2012). Hedges and boosters in academic writing. A study of gender differences in essays written by Swedish advanced learners of English. Unpublished Thesis, Gotensborgs Universitet, Retrieved from http://gyoea.ub.gu.se/bitstream/2077/29626/1.pdf

Silver, M. (2003). The stance of stance: A critical look at ways stance is expressed and modeled in academic discourse. Journal of English for Academic Purposes, 2(4), $359-374$. http://dx.doi:10.1016/S1475-1585(03)00051-1

Stotesbury, H. (2003). Evaluation in research article abstracts in the narrative and hard sciences. Journal of English for Academic Purposes, 2(4), 327-341. http://dx.doi.org/10.1016/S1475-1585(03)00051-1

Swales, J. M., \& Burke, A. (2003). "It's really fascinating work": Differences in evaluative adjectives across academic registers. In P. Leistyna, \& C. F. Meyer (Eds.), Corpus Analysis: language structure and language use (pp. 1-18). Amsterdam: Rodopi.

Swales, J. M., \& Feak, C. B. (2012). Academic writing for graduate students: Essential tasks and skills (3rd ed., p. 331) Ann Arbor: University of Michigan Press.

Varttala, T. (1999). Remarks on the communicative functions of hedges in popular scientific and specialist research articles on medicine. English for Specific Purposes, 18(2), 177-200. http://dx.doi.org/10.1016/S0889-4906(98)00007-6

Wishnoff, J. R. (2000). Hedging your bets: L2 learners 'acquisition of pragmatic devices in academic writing and computer-mediated discourse. Second Language Studies, 19(1), 119-148.

Zareva, A. (2013). Self-mention and the projection of multiple identity roles in TESOL graduate student presentations: The influence of the written academic genres. English for Specific Purposes, 32(2), $72-83$. http://dx.doi.org/10.1016/j.esp.2012.11.001

\section{Appendix: List of authorial stance (Hyland 2005)}

\section{Boosters: verbs, adjectives, adverbs, modals, nouns}

Verbs: believe, be going to, claim, confirm, demonstrate, find, highlight, know, realize, reveal, and show

Adjectives: certain, clear, considerable, demonstrable, definite, evident, noticeable, obvious, significant, sure, 
true

Adverbs: accurately, actually, always, certainly, clearly, completely, considerably, definitely, entirely, especially, essentially, extremely, fully, greatly, heavily, highly, indeed, in fact, necessarily, never, noticeable, obviously, of course, overly, particularly, really, significantly, so, strongly, substantially, surely, too, truly, very, vividly, wholly

Modals: must, will

Nouns: certainty, fact, significance

Hedges: verbs, adjectives, adverbs, nouns, modals

Verbs: appear, assume, guess, hypothesize, indicate, seem, speculate, suggest, suppose, tend

Adjectives: plausible, possible, potential, relative, some, typical, uncertain, unclear, unsure

Adverbs: about, almost, apparently, approximately, around, broadly, commonly, doubtful, fairly, frequently, generally, in general, in most cases, in some cases, in some ways, largely, likely, maybe, mostly, normally, often, on some occasion, overall, perhaps, possibly, potentiallyl, predominantly, presumably, primarily, probably, quite, rather, relatively, roughly, seemingly, sometimes, somewhat, to some degree, to some extent, typically, uncertainly, unclearly, unlikely, usually

Nouns: assumption, hypothesis, indication, possibility, tendency

Modals: can, could, may, might, would

\section{Attitude markers: verbs, adjectives, adverbs, nouns}

Verbs: contribute, deserve, ensure, extend, expand, fail, lack, support

Adjectives: adequate, better, best, central, complex, comprehensive, confident, consistent, core, critical, crucial, dangerous, difficult, easy, effective, essential, fundamental, good, great, hard, hopeful, important, influential, interesting, limited, main, major, meaningful, key, necessary, narrow, new, poor, primary, problematic, promising, reasonable, significant, serious, strict, sufficient, suggestive, tremendous, true, unique, useful, valid, well known, worthwhile

Adverbs: critically, importantly, interestingly, only, surprisingly, truly, usefully, uniquely, unfortunately

Nouns: absence, caution, contribution, limitation, importance, insight, support

Self-mention: I, me, my, we, our, us, the author, the researcher

\section{Copyrights}

Copyright for this article is retained by the author(s), with first publication rights granted to the journal.

This is an open-access article distributed under the terms and conditions of the Creative Commons Attribution license (http://creativecommons.org/licenses/by/3.0/). 